Volume 5, Issue 2, June 2020, pp. 119-129

DOI: $10.23917 /$ jramathedu.v5i2.9545

p-ISSN: 2503-3697, e-ISSN: 2541-2590

\title{
The pattern of a relational understanding of fifth-grade students on integer operations
}

\author{
Dwi Priyo Utomo \\ Department of Mathematics Education, Universitas Muhammadiyah Malang, Indonesia \\ Corresponding author: dwi priyo@umm.ac.id
}

\section{ARTICLE INFO}

Article history:

Received: 17 December 2019

Revised: 24 March 2020

Accepted: 29 March 2020

Published online: 13 may

2020

Published regularly: June

2020

\section{ABSTRACT}

Relational understanding constitutes students' awareness of appropriate procedures to solve problems along with logical reasoning. Itis pivotal to help students solve problems in mathematics. It is necessary that the teaching of mathematics be directed to achieve relational understanding. Accordingly, students are capable of solving complicated problems in mathematics. This current research aims at analyzing and describing relational understanding and the patterns of answering questions of the fifth graders on integer operation. This study used a qualitative approach with a case study as the research design. Further, three students belonging to the fifth grade of Elementary School in Malang City, Indonesia, were set up as the research subjects. A test was administered to measure the subjects' relational understanding. All collected data were analyzed using an interactive technique. The result has indicated that the highly-proficient student was able to show excellent relational understanding. Besides, it was shown that the fairly-proficient student could show good relational understanding. The lowly-proficient student was shown to be able to achieve only half of the holistic criteria set for relational understanding. The patterns of answering the questions demonstrated by all students in all levels included jotting down the models, completing the models, and answering the questions. The highlyproficient student understood the information and wrote it down. Whilst the fairly-proficient student understood the information without translating it into the written form. At last, the lowly-proficient student did not pronounce any signals of understanding of the information

(C) 2020 Universitas Muhammadiyah Surakarta

\section{Introduction}

Skemp (1976) defines two types of mathematical understanding: relational understanding and instrumental understanding. Further, Skemp (2006) asserts that relational understanding constitutes students' awareness of appropriate procedures to solve problems along with the logical reasoning for the choice of those procedures. Besides, Weber (2002) states that relational understanding comprises an understanding of informal concept ideation, concept definition, as well as the reasons why certain concept exists. Instrumental understanding is the ability to appropriately apply any memorized rule to solve a problem without knowing why the rule works (Skemp, 1976). 
Minarni, Napitupulu, and Husein (2016) assert that relational understanding is the ability to deduce specific rules or procedures from a more general mathematical relationship. For example, the product of two numbers with the same sign is positive and that product of two numbers with the different signs is negative. Relational understanding does not focus merely on a set of procedures to arrive at the answers, but it also improves students' understanding of mathematics (Napaphun, 2012). Students are often confused about relational terms, tend to use all numbers in word problems, apply the principles of the wrong operation to reach a final solution, and only possess an instrumental understanding of arithmetic operation on the principles of integers without relational and logical understandings (Yung \& Paas, 2015).

There are four benefits of a relational understanding of mathematics. First, students will be facilitated to solve complicated problems more efficiently. Second, it is easier for students to memorize and comprehend concepts in mathematics. Third, students could achieve the goals of their learning. Fourth, it helps students generate and create original ideas (Skemp, 2006). Accordingly, students should be encouraged to have a relational understanding. To achieve this understanding, they must develop conceptual structures that contain relevant concepts (Star \& Stylianides, 2013).

It takes a long time and teachers' perseverance to develop students' relational understanding. Therefore, equipping students with relational understanding should be initiated from elementary school. For instance, the fourth and fifth graders could be assigned to solve some problems. In this sense, students will develop in these four areas. First, they will develop an understanding of various concepts in mathematics. Second, relational understanding facilitates students to perceive every problem holistically. Third, students are trained to apply a series of principles and concepts in mathematics. Fourth, students will improve their inductive skills (Napaphun, 2012). Researchers of relational understanding focus mainly on its development while learning arithmetic and algebra (Todorova, 2016; Patkin \& Plaksin, 2018; Stephens, 2006)

It is necessary to teach integers to students as the knowledge about integers will facilitate them to solve problems in their daily life (Musser, Burger, \& Peterson, 2005). The integer is an abstract material, considering the existence of negative integer that is rarely found in daily life. Therefore, students tend to find it problematic to calculate. Addition and subtraction are important parts of life and people do not usually go through a day without needing to add or subtract something. Addition and subtraction are also the building blocks for more advanced mathematics (Caron \& Jacques, 2001). However, students still find it difficult to deal with integers. They could not recognize which number is bigger and are confused to decide the correct calculation operation (Van de Walle, Karp, \& BayWilliams, 2008). Almost all of the examples of arithmetic problems in elementary school math curricula incorporate operations (e.g. addition and subtraction) on the left side of the equal sign and the "answer" on the right side (Seo \& Ginsburg, 2003).

There have been some previous researches regarding relational understanding. Anwar, Yuwono, and Rahman ( $\underline{2016})$ postulate that subjects with visual and symbolic representations can build relational understanding. Nevertheless, the visual representation displayed by the subjects on the measurement concept is not accurate. Another research by Safitri, Juniati, and Masriyah (2018) reveals that regarding relational understanding at the stage of understanding the problem, the subjects can state and write what is known and asked and mention key concepts related to rectangular problems. This shows that the relational understanding of the students with high, medium, and low mathematical abilities still needs to be further investigated. 
There were some underlying reasons why this research was carried out. First, this was regarding previous researches that had not attempted to focus on a relational understanding of integer operation at the elementary school level. Second, this current research was considering the importance of teaching mathematics. Therefore, based on the above elaboration, the research problem of this current research was set as "how is the relational understanding practiced on integer operation by the fifth graders in elementary school?" and "how do the fifth graders pattern their strategies for answering questions on integer operation?".

\section{Research Methods}

A case study was employed as the research design. The subjects involved three fifthgraders from one of private Elementary Schools in Malang, Indonesia. They represent three categories: highly-proficient (S1), fairly-proficient (S2), and lowly-proficient (S3).

The data were taken from the test and interview. The test was administered to measure the students' relational understanding with one question regarding integer operation based on the relational understanding indicator. The problems were chosen based on the indicators of competences on integer operation adapted from Davis (2006) as shown in Table 1.

Table 1.

Indicators of relational understanding of integer operation (Adapted from Davis, 2006)

\begin{tabular}{|c|c|c|}
\hline Category & Indicator & Description \\
\hline \multirow{3}{*}{ Procedural } & $\begin{array}{l}\text { Applying a series of procedures } \\
\text { holistically }\end{array}$ & $\begin{array}{l}\text { Applying the basic steps for mentioning initial } \\
\text { temperature, calculating the increasing temperatures, } \\
\text { making a mathematical model, solving the model, and } \\
\text { solving problems }\end{array}$ \\
\hline & Applying procedures smoothly & $\begin{array}{l}\text { Mentioning initial temperature, calculating the } \\
\text { temperatures, writing a model, and solving the model, as } \\
\text { well as answering the final temperature of the ice block } \\
\text { after } 15 \text { minutes }\end{array}$ \\
\hline & Resulting in incorrect answers & $\begin{array}{l}\text { Resulting in the correct answer based on proper } \\
\text { procedures. The temperature of the ice block after } 15 \\
\text { minutes is } 3^{\circ} \text { Celsius. }\end{array}$ \\
\hline \multirow{6}{*}{ Conceptual } & $\begin{array}{l}\text { Showing the ability to apply } \\
\text { procedures }\end{array}$ & $\begin{array}{l}\text { Explaining what is known and asked, making a } \\
\text { mathematical model, and solving the model (finishing the } \\
\text { operation orderly), and answering the problems }\end{array}$ \\
\hline & $\begin{array}{l}\text { Knowing when to apply certain } \\
\text { procedures }\end{array}$ & Knowing when to apply certain operation procedures \\
\hline & $\begin{array}{l}\text { Having prior and pre-requisite } \\
\text { knowledge to apply procedures }\end{array}$ & $\begin{array}{l}\text { Having prior and pre-requisite knowledge to solve } \\
\text { problems of integer, calculation operation, as well as } \\
\text { procedures to calculate integers }\end{array}$ \\
\hline & $\begin{array}{l}\text { Detecting errors when applying } \\
\text { procedures }\end{array}$ & $\begin{array}{l}\text { Detecting errors in calculating integers, positive and } \\
\text { negative signs, as well as the orders in calculation } \\
\text { operation of integers }\end{array}$ \\
\hline & $\begin{array}{l}\text { Providing logical arguments } \\
\text { when applying procedures }\end{array}$ & $\begin{array}{l}\text { Providing logical argument when applying basic steps, } \\
\text { such as showing the procedure to solve a certain problem } \\
\text { and explaining why the procedure is taken }\end{array}$ \\
\hline & $\begin{array}{lrr}\begin{array}{l}\text { Recognizing } \\
\text { problems }\end{array} & \begin{array}{r}\text { new } \\
\text { when }\end{array} \\
\text { procedures } & & \text { applying } \\
\end{array}$ & $\begin{array}{l}\text { Recognizing new types of problems that can be solved } \\
\text { through certain procedures }\end{array}$ \\
\hline
\end{tabular}


An interview guide was used to collect the students' arguments in answering the questions related to integer operation. The unstructured interview was conducted to collect the data.

The problem to investigate the student relational understanding is as follows:

The initial temperature of the ice block in a refrigerator is $-7^{\circ} \mathrm{C}$. After being taken out from the refrigerator, the temperature rises $2^{\circ} \mathrm{C}$ every 3 minutes. What is the temperature of the ice block after 15 minutes?

There were three activities to analyze the data: reduction, presentation, and drawing conclusions. All activities were carried out in parallel during the process of collecting the data. The data reduction activities on interview results were performed by the following. Firstly, summarizing the interview results in the form of note-taking or record the information from the students. Secondly, sorting out the data between the most and least important based on indicators had determined. Finally, the most important data were analyzed. The main role of the interview was to reveal deeply the information about the relational understanding of integer operation.

The data were presented in a descriptive based on the reduction activities. It makes easier to understand what happened in the systematic organization of the data. The conclusion drew by the researcher should be supported by valid data. In this phase, the conclusion would be based on the results of the analysis of the whole data.

\section{Results and Discussion}

\section{Case 1: Highly-proficient Subject (S1)}

Figure 1 shows the excerpt of answering the problem of the highly-proficient student.

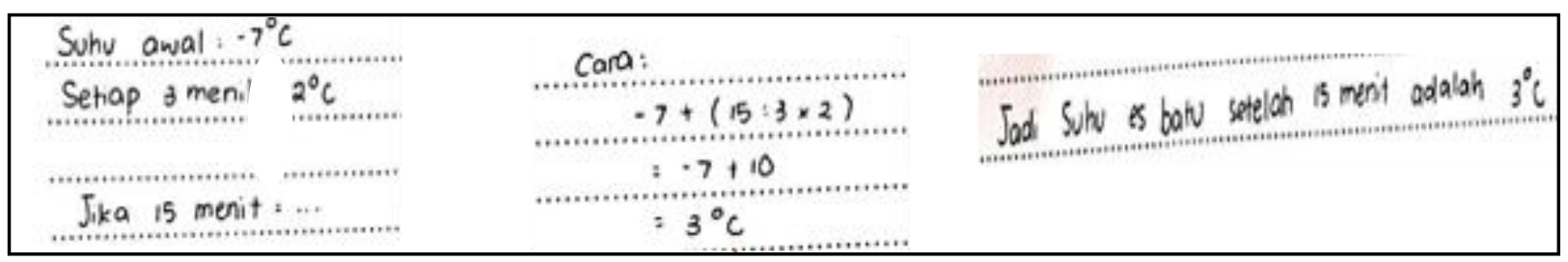

Figure 1. The excerpt of highly-proficient student answer

Figure 1 indicates that S1 was able to perform the procedure correctly. The subject had mentioned what had been identified, what was questioned, and how to answer along with the mathematical model. Afterward, S1 was completed the model and solved it correctly. This was supported by the interview excerpt with the student.

\footnotetext{
Researcher : What does the expression of "in 15 minutes ..." imply?

S1 : It refers to "the final temperature after 15 minutes."

Researcher : Why is it written "-7+(15:3x2)? Could you please explain it?

S1 : The initial temperature is $-7^{\circ} \mathrm{C}$, isn't it? Then, it requires us to find out the temperature after 15 minutes. That is why I should add $-7^{\circ} \mathrm{C}$ to the temperature after 15 minutes.

Researcher : Then?

S1 : As in every 3 minutes, the temperature rises $2^{\circ} \mathrm{C}$, the temperature after 15 minutes will be obtained when 15 is divided by 3 . Then, the result of the division should be multiplied by $2^{\circ} \mathrm{C}$. The final result of the calculation is to be added to the initial temperature.
} 
The interview excerpt showed that the patterns of answering the question include writing down the information that is known and asked, constructing a mathematical model, completing the model, and answering the question. All the procedures were stated clearly and comprehensively. The model constructed by S1, $(-7+(15: 3 \times 2))$, had shown the order of time and pattern of answering the question. The initial temperature, $\left(-7^{0} \mathrm{C}\right)$, was added by the temperature after 15 minutes, $\left((15: 3 \times 2)^{0} \mathrm{C}\right)$. Then, $\mathrm{S} 1$ performed a division operation, followed by multiplication. Furthermore, S1 completed the operation in the bracket preceding the addition operation.

The effectiveness of the student in doing the procedure has shown by his performed in solving the problem. The student could answer the problem quickly with no interference during the answering process. S1 has been identified as the information and questions in the problem, constructed the mathematical model, and performed the procedures to solve the problem. Afterward, S1 could complete the problem correctly and effectively. The interview excerpt showed that the subject was not interfered with by any problem in applying the procedure.
Researcher
Do you find it difficult to answer?
S1 : No, Sir. I have been accustomed to answering in such a way for integer operation and had done the same thing before

The student also has performed correctly in every step of solving the problem. He could successfully communicate the identified information, how to answer, and the solution to the problem given. The student also demonstrated the ability to explain the procedure for solving the question. That ability showed in the excerpt of the student answer in the interview.

"It is told that the temperature increases $2^{\circ} \mathrm{C}$ in every 3 minutes. The final temperature is sought after 15 minutes. As in every 3 minutes, the temperature rises $2^{\circ} \mathrm{C}$, I divided 15 by 3 , which is 5.5 should be multiplied by 2 , which is 10 . At last, 10 is added with the initial temperature of $-7^{0} \mathrm{C}$. Therefore, the result is $3^{\circ} \mathrm{C}^{\prime \prime}$

Besides, S1 knew when to use the correct procedure to calculate the initial temperature, $7^{\circ} \mathrm{C}$. The subject could calculate the increasing temperature per 3 minutes by dividing 15 by 3 and then multiplying it by 2 . Furthermore, $S 1$ obtained the model, $-7+(15: 3 \times 2)$. Then, the student answer is $3^{\circ} \mathrm{C}$ as the solution to the problem. An interview with the subject has revealed that S1 knew when to apply the correct procedure.

\footnotetext{
Researcher : Explain the steps for solving the problem

S1 : I divided 15 by 3 , resulting in 5 . Then, I multiplied 5 by 2 , resulting in 10 . I added $10^{\circ} \mathrm{C}$ with an initial temperature of $-7^{\circ} \mathrm{C}$. The results is $3^{\circ} \mathrm{C}$
}

Furthermore, S1 possessed pre-requisite knowledge in solving the operation of integer problem. The knowledge comprises integer, time, temperature, addition, subtraction, multiplication, and division. An interview with the subject has revealed that S1 utilized the knowledge to solve the problem.

\footnotetext{
Researcher : What are the operations used to solve this problem?

S1 : Addition, substraction, multiplication, and division

Researcher : Other than time unit, is there another unit in that problem?

S1 : The unit of temperature, which is the celcius degree
} 
Figure 1 also showed that S1 did not make an error in performing the calculation. An interview with the subject has revealed that S1 was aware of the inexistence of error in the calculation.
Researcher
: Do you know that there is an error in your operation procedures?
S1
: After rechecking, I do not find any error in the process of calculation, Sir.

The subject also demonstrated his logical arguments when applying the operation procedures of integers. The subject could show and explain the steps of finding out the temperature after 15 minutes. He also recognized a new type of problem to be solved through proper operation procedures of integers. Then, this subject successfully identified that the problem could be solved by addition and multiplication operations. This finding has also been confirmed by an interview with the subject.

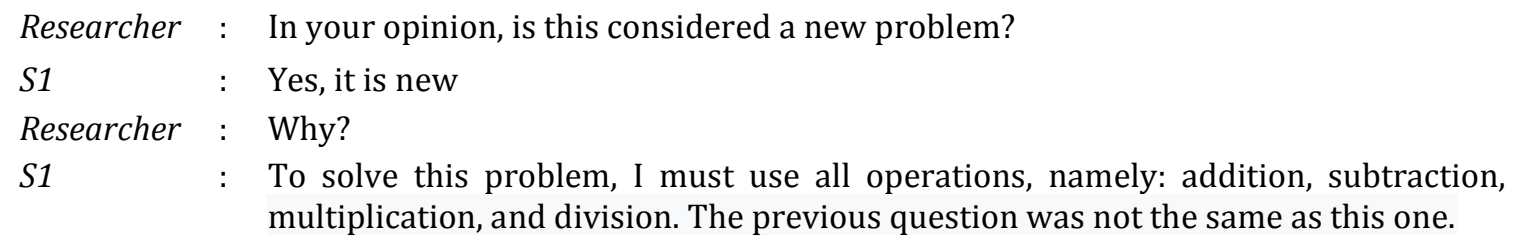

Based on the data analysis, the highly-proficient student (S1) showed the ability to operate effectively, generate the answer correctly, and perform the procedure accurately. Besides, S1 knew when to apply the procedure and anything required to apply the procedure. The student was aware of errors in applying the procedure. He succeeded in accurately giving a logical argument and recognizing a new type of question that could only be solved using specific operating procedures. Based on the description above, it can be concluded that S1 showed excellent relational understanding to perform the operation procedure of addition.

\section{Case 2. Fairly-proficient Subject (S2)}

Figure 2 shows the excerpt of answering the problem of the fairly-proficient student.

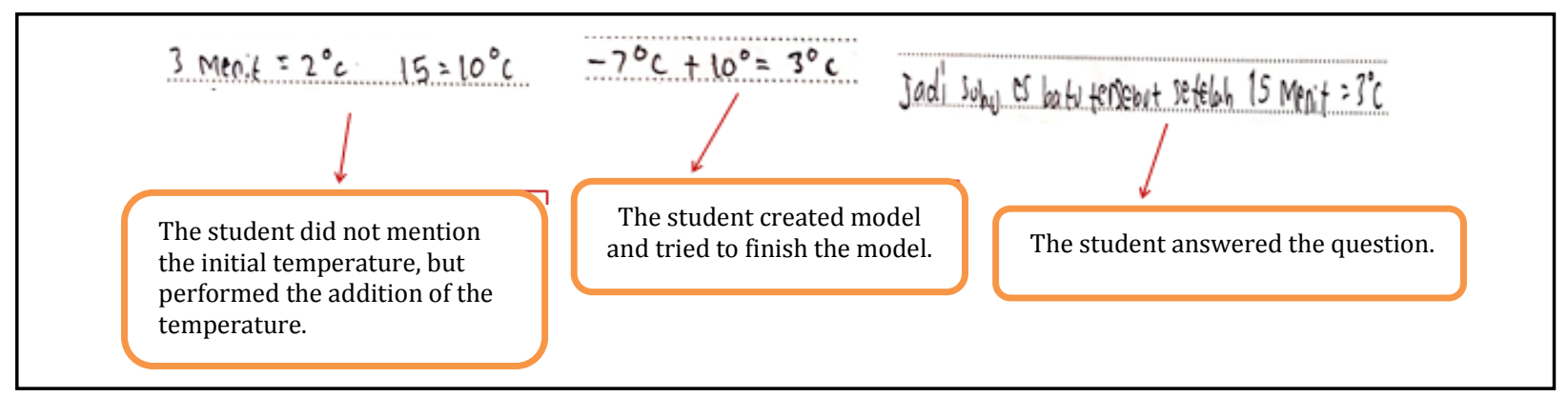

Figure 2. The excerpt of fairly-proficient student answer

Figure 2 indicates that S2 could not write the information in the problem completely. He only wrote down the additional temperature per 3 minutes but to be mistaken in expressing it. Besides, the student was able to create the mathematical model even though partially. He calculated the added temperature after 15 minutes separately. In the next step, S2 calculated the initial temperature of $-70^{\circ} \mathrm{C}$ added by a total of temperature after 15 minutes. Overall, S2 could solve the problem correctly. This information was supported by the excerpt from the interview as follows. 


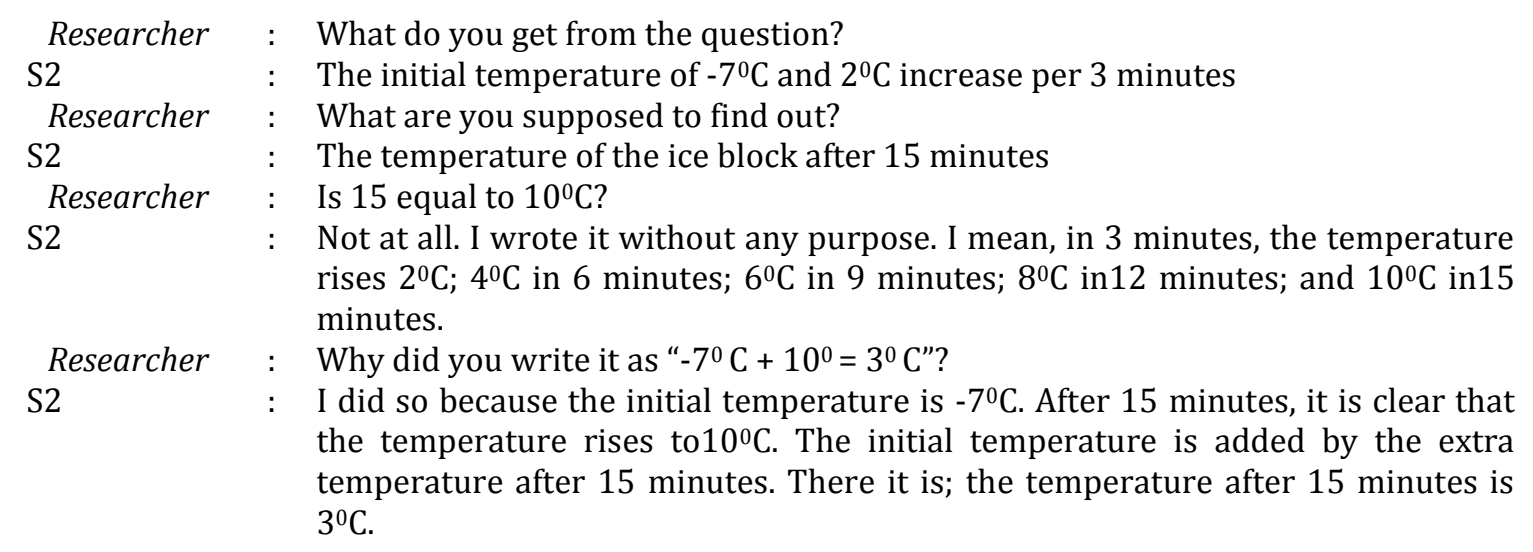

The interview result showed that the pattern of solving the problem demonstrated by S2 encompasses: writing down the information that was known, designing mathematical models partially, completing the model partially, and answering the questions. However, he did not write down the information questioned. The student has shown a good understanding of what was informed and questioned. Besides, the student has being able to answer the question correctly. Despite, the subject could not transform the information and question the problem into a mathematical model correctly. Interestingly, the student did not use of the mathematical model completely like S1. Instead, he used a partial model before combining it. Even more, S2 did not apply the operation concept of division and multiplication to calculate the increase of the temperature after 15 minutes. Instead, S2 applied a repeated addition to the temperature per 3 minutes.

The subject was also shown to be quite effective in doing the procedure in solving the problem. His procedure to answer the question was considerably fast. He did not find obstruction when solving the problem. S2 could mention the identified properties, but not the questioned one. The subject was also able to create a mathematical model before answering the question. This was supported by the data from the interview as follows.

"No, Sir. I have been accustomed to answering the question regarding integer this way before."

Furthermore, Figure 2 demonstrates that S2 could find out the right answer on every single step. It was shown particularly when stating the identified properties, making a judgment on the result of the procedure, and showing up the final answer to the question given. The subject showed the capability of explaining the steps of implementing the procedure to answer the question which is demonstrated on the following result of the interview.

\footnotetext{
"It is informed that the temperature increases $2^{\circ}$ in every 3 minutes. The question asks for the final temperature after 15 minutes. After 3 minutes, the temperature rises to $2^{\circ} \mathrm{C}$. After 6 minutes the temperature rises to $4^{\circ} \mathrm{C}$, and so on. After 15 minutes, the temperature rises to $10^{\circ} \mathrm{C}$. Then I add $-7^{\circ} \mathrm{C}$ to $10^{\circ} \mathrm{C}$ and get $3^{\circ} \mathrm{C} . "$

The data analysis revealed that the fairly-proficient student has shown relatively good relational understanding to perform the addition operation even though inaccurate. The subject could operate the procedure effectively and know when to use it. He knew that the pre-requisite knowledge was needed to use the procedures and recognize the errors made in the solving steps. This subject could also give a logical argument why such a procedure was worth doing and recognize a new type of question that could be solved by
} integer operation. 


\section{Case 3: Lowly-proficient Subject}

Figure 3 shows the excerpt of answering the problem of the lowly-proficient student.

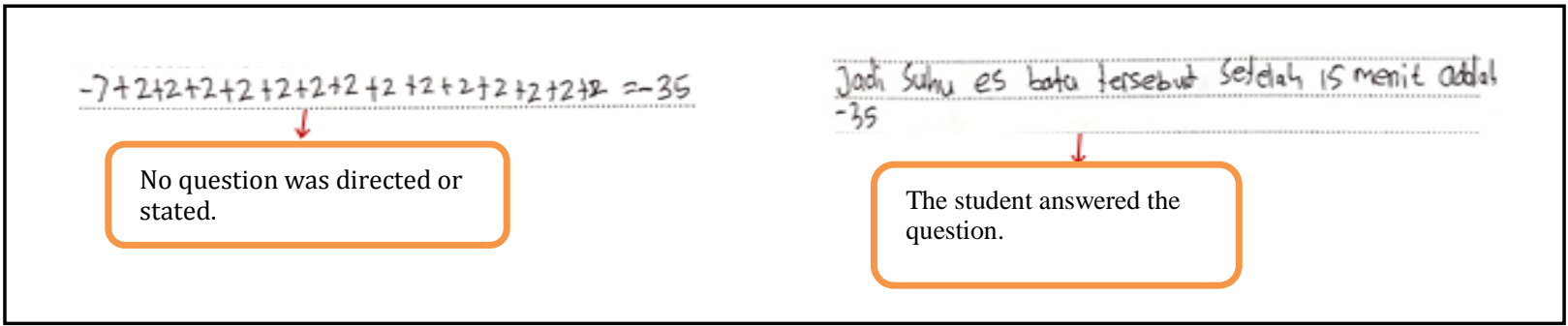

Figure 3. The excerpt of lowly-proficient student answer

Figure 3 showed that S3 was unable to perform the procedure correctly. The subject could not even mention the identified properties, the questioned problem, and the procedure to be solved the problem. The student has tried to create a model even though incorrect. Afterward, the subject attempted to solve the model to find out the solution but was still erroneous. This pattern was underpinned by the interview result as follows.

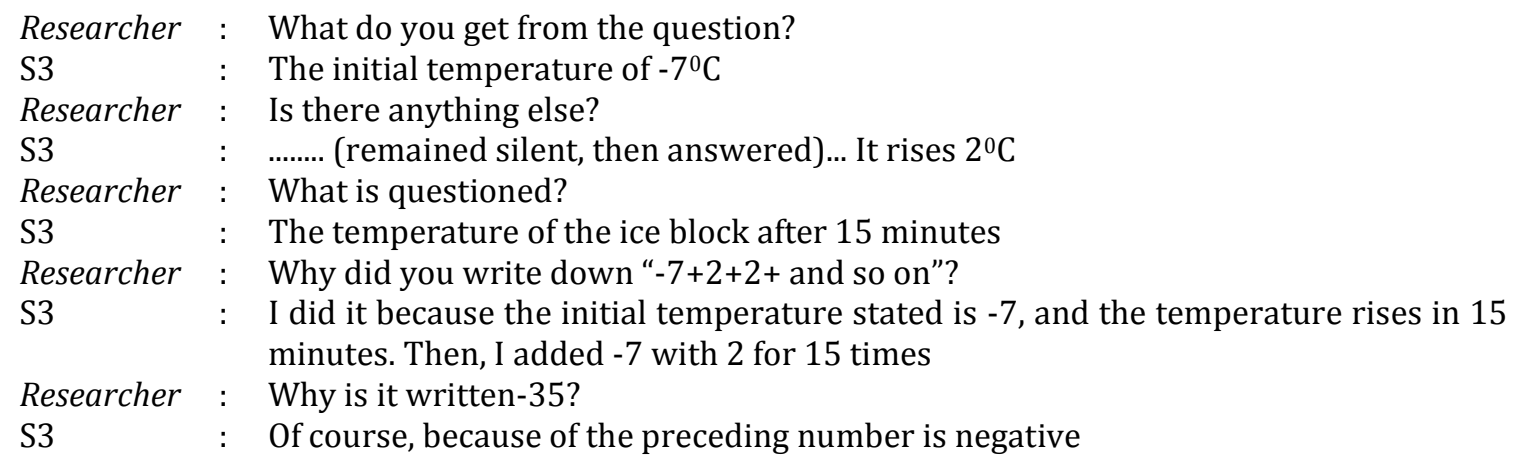

Based on the interview result, it is clearly shown that the pattern of answering the question demonstrated by S3 is as follows: did not write what was informed or questioned and attempted to design a mathematical model even though being mistaken. The subject has understood the initial temperature. However, he did not understand the increase in temperature every 3 minutes. Besides, S3 also understood what was questioned. Remarkably, the student attempted to design an addition operation started by -7 , then adding it with 2 to 15 times. The subject did not understand the meaning of $2^{0} \mathrm{C}$ increase each 3 minutes (the concept of multiplication). He also was mistaken by replacing 15 minutes with 15 times (the concept of time). Further, S3 could not perform the addition operation using negative integers.

Besides, S3 could not perform the procedure effectively. It can be seen from a similar pattern with unable to perform the procedure correctly. This is supported by the interview result as follows.

"I just do everything based on the given instruction, by adding all numbers given."

Figure 3 also showed that the subject used the wrong procedure to solve the problem. It can be seen from the results of his identified information, the result of the process, and the answer to the question. S3 has shown the inability to explain the procedure of answering the question. It was shown from the following excerpt from the interview.

"I haven't successfully found out the correct procedure to answer the given question." 
The lowly-proficient student (S3) showed inadequate relational understanding. The subject could not operate the procedures correctly. S3 did not know when to use the procedure precisely and could not identify the pre-requisites needed for doing the procedure. He was not aware of the errors made while performing the procedure. Besides, S3 could not give a logical argument and recognize a new type of question that could be solved with specific procedures.

The highly-proficient student was equipped with excellent the relational understanding, the fairly-proficient student was good, while the lowly-proficient student was relatively deficient. The students with highly- and fairly-proficient mathematical abilities have been equipped with good relational understanding. On the contrary, those with lowly-proficient ability were shown to be less in relational understanding. The students with highly- and fairly- proficient abilities could synthesize a concept procedurally and explain the concept systematically. This is in line with research by Safitri et al. (2018) that there are differences in relational understanding in solving problems among the students.

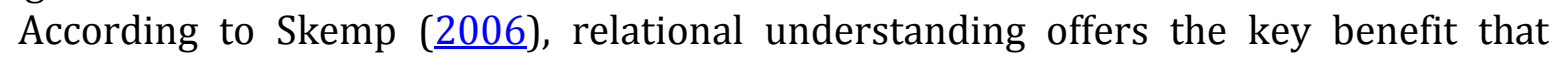
functions as a tool to facilitate mathematics learning. The higher students' relational understanding, the easier they solve problems in mathematics. Therefore, students could achieve the goals of their learning. In other words, those who are equipped with low relational understanding would be difficult to achieve the goal. On the one hand, according to John, Jennifer, Louann, and Karen ( $\underline{2014}$ ), relational understanding is defined as any novel concept or procedure that does not only need understanding but ideas and knowledge as well to make learners be able to find out several connections as expected. Instrumental understanding occurs due to the students' failure to meet a half or the whole indicators set up for relational understanding as proposed by Davis ( $\underline{2006})$. Moreover, Skemp (as cited by Walle V. De \& John, 2008) claims that instrumental understanding exists since the students do not have an adequate conceptual understanding. In other words, the procedural knowledge they possess could not accommodate their conceptual understanding.

The typical pattern of answering the question demonstrated by the highly-, fairly-, and lowly-proficient students included constructing the mathematical model based on the question, completing the model, and answering the question. All students understood what was questioned, but not all of whom understood the information implied by the question itself. The highly-proficient student understood the information and was able to state it correctly and comprehensively. The fairly-proficient student could understand the information stated in the question, but was not able to translate it into a written form correctly. Meanwhile, the lowly-proficient student appeared to be incapable of understanding the implied information and stating it in a written form.

In answering the question, the highly-proficient student was shown effective in operating addition, multiplication, and division. The fairly-proficient student skipped multiplication and division but kept operating addition recurrently. Meanwhile, the lowlyproficient student tried to operate addition when answering the question but remained unable to operate the addition using a negative integer.

\section{Conclusion}

The following section sums up the patterns of students' relational understanding in solving problems. The student with high ability could perform the procedure of operation relatively well and effectively. Therefore, the problem can be solved properly and correctly. The pattern of answering the question is consisted of jotting down what was informed and 
questioned, structuring/designing a mathematical model, completing the model, and answering the question. To complete the mathematical model, the student-operated addition, multiplication, and division.

The student with fair ability could show up good relational understanding since the student had been able to operate the procedures correctly. He knew when to apply specific procedures and utilize the pre-requisite knowledge to perform the procedures. The student with this sort of fair ability did not know errors might potentially occur. However, the student could come up with logical arguments regarding the performed procedures. Besides, this type of student succeeded in recognizing a new type of problem that could be solved by certain procedures. The pattern included partially writing down what was informed, structuring a mathematical model, completing the model part by part, and answering the question. The student had a good understanding of the question. He was also able to answer the question even though could not write the answer correctly. The student only used repeated addition to complete the mathematical model.

The student with low ability has shown poor relational understanding. The student could not perform the procedures smoothly and unable to find the answer to the problem. Besides, He did not know when to apply certain procedures and possess pre-requisite knowledge. The student could not identify any errors that might occur and provide logical arguments when applying certain procedures. Therefore, the failing to recognize a new type of problems were susceptible to occur. The student constructed a mathematical model directly preceding the answer to the question. He also did not understand the information stated in the question, unable to operate an addition using negative integers, and did not understand the concept of multiplication. The student performed repeated addition in completing the mathematical model. The pattern of students' relational understanding in solving problems as described above is important and interesting to study. Therefore, the next researchers can continue this current research to investigate students' relational understanding patterns on other topics.

\section{Acknowledgment}

The researcher would like to thanks to the teacher of Insan Amanah Primary School of Malang, Mr. Sofyan for helping to collect the data and Mr. Teguh Santoso for processing the data

\section{Bibliography}

Anwar, R. B., Yuwono, I., \& Rahman, A. (2016). Mathematical representation by students in building relational understanding on concepts of area and perimeter of rectangle. Educational Research and Reviews, 11(21). 2002-2008. https://doi.org/10.5897/ERR2016.2813

Caron, L., \& Jacques, P. (2001). Addition and subtraction. New York: Enslow Publisher, Inc.

Davis, E. J. (2006). A Model for Understanding in Mathematics. Mathematics Teaching in the Middle School, 12(4), 1-13. Retrieved from https://eric.ed.gov/?id=EJ765704

John A, V. de W., Jennifer M, B.-W., Louann H, L., \& Karen S, K. (2014). Teaching StudentCentered Mathematics: Developmentally Appropriate Instruction for Grades 6-8 (Volume III) 3rd Edition. Boston: Pearson.

Minarni, A., Napitupulu, E. E., \& Husein, R. (2016). Mathematical Understanding And Representation Ability Of Public Junior High School In North Sumatra. Journal on Mathematics Education, 7(1), 43-56.http://dx.doi.org/10.22342/jme.7.1.2816.43-56

Musser, G. L., Burger, W. F., \& Peterson, B. E. (2005). Mathematics for Elementary Teacher. 
USA: John Wiley \& Sons, Inc.

Napaphun, V. (2012). Relational Thinking: Learning Arithmetic in order to Promote Algebraic Thinking. Journal of Science and Mathematics, 35(2), 84-101. Retrieved from http://www.recsam.edu.my/sub_JSMESEA/images/journals/YEAR2012/ dec2012vol-2/84-101.pdf

Patkin, D., \& Plaksin, 0. (2018). Procedural And Relational Understanding Of Pre-Service Mathematics Teachers Regarding Spatial Perception Of Angles In Pyramids. International Journal of Mathematical Education in Science and Technology, 1-20. https://doi.org/10.1080/0020739X.2018.1480808

Safitri, A. N., Juniati, D., \& Masriyah. (2018). Students' Relational Understanding in Quadrilateral Problem Solving Based on Adversity Quotient. Journal of Physics. 947(1). 1-6. https://doi.org/10.1088/1742-6596/947/1/012039

Seo, K.-H., \& Ginsburg, H. P. (2003). The development of arithmetic concepts and skills: Constructing adaptive expertise. Mahwah, NJ: Erlbaum.

Skemp, R. R. (1976). Relational Understanding and Instrumental Understanding. Mathematics Teaching, 77(1), 20-26. Retrieved from http://www.davidtall.com/skemp/pdfs/instrumental-relational.pdf

Skemp, R. R. (2006). Relational Understanding and Instrumental Understanding. Journal National Council of Teachers of Mathematics (NCTM), 12(2), 88-95. Retrieved from https://eric.ed.gov/?id=EJ765695

Star, J. R., \& Stylianides, G. J. (2013). Procedural and Conceptual Knowledge: Exploring the Gap between Knowledge Type and Knowledge Quality. Canadian Journal of Science, Mathematics and Technology Education, 13(2), 169-181. https://doi.org/10.1080/14926156.2013.784828

Stephens, M. (2006). Describing and Exploring the Power of Relational Thinking. Proceedings of the Mathematics Education Research Group of Australia Incorporated (pp. 479-486). Australia: University of Melbourne.

Todorova, A. D. (2016). Procedural and Conceptual Understanding in Undergraduate Linear Algebra. Proceedings of the First Conference of International Network for Didactic ( $p p$ 1-12). Montpellier (France): University Mathematics. Retrieved from https://hal.archives-ouvertes.fr/hal-01337932/document

Van de Walle, J., Karp, K. S., \& Bay-Williams. (2009). Elementary and Middle School Mathematics, Teaching Developmentally. USA: Pearson.

Walle, V. De, \& John, A. (2008). Elementary and Middle School Mathematics: Teaching Developmentally, 6th edition. Pearson: Boston New York.

Weber, K. (2002). The Role Of Instrumental And Relational Understanding In Proofs About Group Isomorphism. In K. Weber (Ed.), Proceedings from the 2nd International Conference for the Teaching of Mathematics (pp. 1-9). New Jersey: The State University of New Jersey.

Yung, H. I., \& Paas, F. (2015). Effects of computer-based visual representation on mathematics learning and cognitive load. Educational Technology \& Society, 18(4), 70-77. Retrieved from https://ro.uow.edu.au/cgi/viewcontent.cgi?article= 2940\&context=sspapers 